\title{
Analysis and Prevention of Ship Air Pollution in Yangtze River Delta
}

\author{
Huiling Guo
}

\author{
Tianjin Maritime College, Tianjin Haihe Educational Park,Jinnan District, Tianjin, China \\ email : guoguo3425@126.com
}

\begin{abstract}
Keywords:Yangtze River Delta Area, ship air pollution, problems analysis, the prevention measures.
\end{abstract}

\begin{abstract}
The paper introduces the status and harm of ship air pollution in Yangtze River Delta, and expounds the regulations and policies of ship emission control in this area. In this paper, the problems of air pollution prevention and control for ships in Yangtze River Delta are analyzed, and the preventive measures of air pollution for ships are put forward.
\end{abstract}

\section{Introduction}

It is an important national strategy to promote the development of the Yangtze River Economic Belt, but with the rapid growth of the economy and shipping industry, the environmental pollution caused by ships in the Yangtze Delta has become more and more serious, especially the problem of atmospheric pollution has seriously restricted the normal production and life of people.

\section{Status and harm of ship air pollution in Yangtze River Delta}

Yangtze River Delta is rich in shipping resources. According to the 2016 Statistical Bulletin of Traffic and Transport Industry issued by the Ministry of Communications and Transport, there are 27 observation sections of water traffic flow along the main channel of the Yangtze River. The annual average daily volume of vessels is 662.6, an increase of 2.3 percent over 2016, which indicates that the transportation demand is strong year by year.

By the survey of the Yangtze River Delta Institute of Environmental Sciences, the contribution rate of all kinds of ships to the discharge of various pollutants is $60 \%$ $90 \%$ and it is the main emission source in this region, it is found that the largest contribution rate of ship emissions is $\mathrm{SO}_{2}$ emissions in $94 \%$. The emission of these pollutants is a great threat to the atmospheric environment and human health, among which sulfur dioxide is the main factor in the formation of acid rain, and it can damage the lungs and myocardium of human and animal. NOx and HC is an important source of photochemical smog. Gases such as $\mathrm{C0x}$, CO may cause Greenhouse Effect, which is global warming; Diesel particulate matter in diesel engine smoke has been identified as a carcinogen by the World Health Organization (WHO) Cancer Research Institute.

\section{Regulations and policies on the discharge control of ships in Yangtze River Delta}

There are relatively few laws and regulations on the prevention of air pollution caused by ships in China, which are mainly provided in the Marine Environment Protection Law and The Air Pollution 
Prevention and Control Law of the people's Republic of China in separate chapters.

In order to promote the development of green shipping, energy saving and emission reduction of ships, the Ministry of Transport promulgated and implemented the Implementation Plan of Marine discharge Control Zone in the Waters of Pearl River Delta, Yangtze River Delta and the Bohai Sea (Beijing-Tianjin-Hebei)On December 2nd 2015(hereinafter referred to as "The Implementation 2015") “The Implementation 2015" formulates the working objectives and principles of the discharge control area as well as the applicable objects and protective measures.

In addition to the above provisions, the Central Committee of the Communist Party of China convened a meeting on March 25, 2016 to consider the adoption of the Outline for the Development Planning of the Yangtze River Economic Belt, which pointed out that it is necessary to adhere to the ecological priority and green development to strictly control the pollution of ships. The Outline provides policy support and principle requirements for the green shipping.

\section{Problems in the prevention and control of ship air pollutants in Yangtze River Delta}

\section{The relative lag in technical level of marine engines}

Ihe industry technical level of marine engine in China is relatively backward. At present, the low-speed diesel engine, high speed diesel engine is almost monopolized by foreign countries, and the domestic manufacturers are rare, the capacity of independent innovation is weak, new products and new technology development motivation progress is slow. The varieties and diameter (160-400 $\mathrm{mm}$ )of diesel engine products in domestic is dense distribution but function is single and technology is backward, which only for coastal ships and fishing boats. Most of the coastal and inland navigation vessels in Yangtze River Delta almost use the small and medium sized ship diesel engine of high energy consumption and low efficiency because of the old ship and the tonnage is relatively small, and even some small hanging paddle motor boat with a single cylinder diesel engine, obviously the technology is backward, the exhaust gas emission is great and the pollution is serious.

\section{The low quality of ship's fuel}

In accordance with the provisions of annex VI of MARPOL73/78, from January $1^{\text {st }} 2012$, crude oil of any ship in the world with the upper limit of the fuel sulfur content from $4.5 \%(\mathrm{~m} / \mathrm{m})$ reduced to $3.5 \%(\mathrm{~m} / \mathrm{m})$, after January $20201 \mathrm{st}$, it fell to $0.5 \%(\mathrm{~m} / \mathrm{m})$. Influenced by the characteristics of crude oil and market environment factors, China still relies on imported fuel oil for ocean-going ships, which sulfur content is about $2.5-3.5 \%$.

Domestic coastal shipping lines mainly use heavy fuel oil and light fuel oil, mainly processed and produced by domestic enterprises to mix fuel, according to the different components, the sulphur content is about $0.2 \%-2.0 \%$, some products as high as $3.5 \%$. At present, the market of marine diesel oil supply in Yangtze River Delta is relatively chaotic. Although oil suppliers such as Sinopec can supply marine diesel oil to meet the requirements of national standards, there are still a large number of shipping oil suppliers in the market to supply low standard marine diesel oil. In order to reduce the cost, most small boats are also more likely to buy such substandard diesel fuel. In addition, as ocean ships and river sea ships become larger, the proportion of oil demand and actual supply is increasing year by year. The quality of oil directly affects the discharge level of air 
pollutants, the air pollution caused by heavy oil can be seen.

\section{The inadequate functional oversight}

First of all, the regulatory system is lags behind. The laws, regulations and supporting standards for the prevention and control of air pollution still can not meet the demand of pollution prevention and control. Especially, the regulations for preventing ship pollution in inland waters are of low level, lack of supporting technical standards, and of imperfect regulations system. Although the prevention and control of air pollution of ships has made a breakthrough, the foundation is still weak, which is incompatible with the high sensitivity of the water environment in Yangtze River Delta, the severe situation of air pollution and the high attention of the public.

Secondly, the monitoring means are backward. At present, foreign air pollution monitoring technology and equipment are relatively mature, but in China are still blank. Most of the monitoring technology and equipment are still in the stage of R \& D or R \& D but have not been applied in the field of ships. Therefore, the maritime management departments generally is lack of effective, convenient and rapid monitoring means, unable to support grass-roots enforcement actions.

Third, the shortage of professional personnel. The issue of the ship pollution monitoring ability can not keep up with the development of the new situation is increasingly prominent. Due to the lack of standards and systems, the management of ship air pollution is seldom carried out in the daily work, and the team of expert management personnel has not yet been established.

\section{The prevention measures of ship air pollution in Yangtze River Delta}

\section{Compliance with and implementation of the Convention and Regulation related discharge standards for air pollution of ships}

First, strict adherence to the relevant provisions of Annex VI of MARPOL Convention 73/78. According to Annex VI of MARPOL73/78, the ship shall take measures to control the ozone depleting substances (NOx), nitrogen oxides, sulfur oxides, volatile organic compounds (VOCs) emissions, and make restrictions on shipboard incineration operations. At the same time, the convention has also made a clear record book provisions. In March 2006 China joined the Convention and entered into force on August 23rd in China. As a party to the Convention, our country is obliged to fulfil the requirements of the Convention and is responsible for the prevention and control of air pollution of ships.

Second, implementation of the Limit standard to discharge of sulfur oxide ( SOx ) in accordance with the requirements of the Scheme.

The objectives of “The Implementation 2015" from January 1st 2013 to December 31st 2017 has been gradually completed, and the objective from September 1st 2017 will be carried out in advance in Yangtze River Delta emission control area, that is, all ships after arrive at port should replace low-sulfur fuel or use shore electricity or take alternative measures such as tail gas post- treatment. According to this implementation, since January 1st 2018, ships in the discharge control area should ues the oil with sulphur content $\leq 0.5 \% \mathrm{~m} / \mathrm{m}$ during port berthing (except one hour after port arrival and one hour before departure). According to document (2015) 177 issued by the Maritime Bureau 
of the Ministry of Communications, by December 31st 2019, the effectiveness of the control measures will be evaluated to determine whether the following actions will be taken :

1. The ship enters the emission control area using fuel with sulphur content of less than $0.1 \%$ $\mathrm{m} / \mathrm{m}$;

2. Expanding the geographical scope of the emission control area;

3. Other further initiatives.

\section{Actively promote the application of low sulfur oil and LNG fuel}

Low-quality fuel oil is an important source of air pollution emissions from ships. To promote the use of clean energy such as low-sulfur oil and LNG, can effectively control the emission of atmospheric pollutants during ship navigation and berthing. On one hand, it is necessary to solve the problem of oil supply from the source by improving the supply of low-sulfur fuel, strengthening the source supervision of fuel quality, banning non-standard fuel, and implementing low-sulfur oil subsidies or taking other measures. On the other hand, we should speed up the pace of the use of LNG fuel by ships and improve the system construction of port LNG filling facilities, promote the application of LNG in ship and port pilot projects, and the scope of use of LNG in Yangtze River Delta should be expanded step by step.

\section{Strengthen systematic Construction of Coastal electricity use}

The ship shore electricity is the first choice for energy conservation and emission reduction in the port, which is being widely paid attention. With the completion of the 8000-box container ship "M.V. Changqing" under the company of Taiwan's Changrong Company, the coastal electric equipment developed jointly by the Lianyun Port and the Shanghai Port has been successfully powered. But there is a lack of compulsory extension measures in the country, which making the industrialization work difficult. It is necessary to try to establish the "shore electricity use demonstration area" as soon as possible, explore the "shore electricity use cost allocation mechanism" and the necessary funds for the country subsidies, so as to straighten out the coastal electricity collection mechanism, in order to improve the use of coastal electricity by ship.

\section{Speed up the upgrading of ship and port industry}

We should speed up the phase-out of old and backward ships, impose the elimination of high-emission marine diesel engines within a time limit, and prohibit the new establishment substandard vessels to enter the transport market. At the same time, we should encourage energy-efficient and environmentally friendly vessels to build, revampe processing equipment, promote energy efficiency and technology upgrading of the port, promote the use of selective catalytic reduction units such as SCRX, DPF and other reprocessing units, so as to effectively reduce the emission level of pollutants from ships.

\section{Reference}

[1] Ministry of Communications and Transport Science Research Institute.Survey of Air Pollution Prevention and Control of Ships and Ports in China. 2013.3

[2] Ministry of Communications and Transport of the people's Republic of China. Implementation Plan of the Special Action for Port pollution Prevention and Control 2015-2020 (2015-08-27). 
[3] Ministry of Communications and Transportation of the people's Republic of China .Implementation Plan of Marine discharge Control Zone in the Waters of Pearl River Delta, Yangtze River Delta and the Bohai Sea (Beijing-Tianjin-Hebei) [Z] .2015-12-02. 